\title{
Technology of proper use of saline soils in the conditions of Uzbekistan
}

\author{
$B$ Tukhtashev ${ }^{1, *}, U$ Norkulov $^{1}$, and $B$ Izbosarov ${ }^{1}$ \\ ${ }^{1}$ Tashkent State Agrarian University, University str., 2, Tashkent Province, 100140, Uzbekistan
}

\begin{abstract}
In the effective use of saline soils, it is advisable to plant sunflower, corn, beetroot and other crops resistant to soil salinity. At the same time, it is necessary to plant domestic and imported crops such as millet, amaranth, and African sorghum as secondary crops in these soils. These crops, even in saline soils, can contribute to the development of livestock in Uzbekistan by producing 400-500 q/ha, and even higher yields. Most importantly thousands of hectares of land that have fallen out of agricultural use will be re-introduced into the farming system. This is one of the current issues of today. In solving this problem, the resistance to salinity, yield and product quality of agricultural crops (alfalfa, sunflower, white sorghum, sorghum, beet) grown on weak, moderate and strongly saline soils are studied and scientifically substantiated. Technologies for growing these crops will be developed depending on soil and climatic conditions and salinity levels.
\end{abstract}

\section{Introduction}

Growing field crops in saline soils and increasing their salt resistance is a pressing issue in land reclamation. In these conditions, it is important to increase the flexibility and resistance of field crops to salinity on the basis of the use of advanced technologies, as well as to pay special attention to soil reclamation [1-3].

Over the last 20-25 years, for various reasons, large areas of arable land in Uzbekistan have been leaving the agricultural system $[3,5]$. The reasons for this are the lack of manpower in the field, the lack of reclamation equipment, the deterioration of the reclamation of soils, the acceleration of the salinization process, and most importantly, the neglect of land $[4,5,7]$. It is known that the neglect of irrigated lands for many years, leaving them uncultivated, leads to the deterioration of the reclamation of soils, and, most importantly, their re-salinization, swamping, desertification, turning them into reclamation inconvenient areas [6].

In the effective use of saline soils, it is advisable to plant sunflower, corn, beetroot and other crops resistant to soil salinity. At the same time, it is necessary to plant domestic and imported crops such as millet, amaranth, and African sorghum as secondary crops in these soils $[6,8]$. These crops, even in saline soils, can contribute to the development of livestock in Uzbekistan by producing 400-500 q/ha, and even higher yields. Most importantly

\footnotetext{
${ }^{*}$ Corresponding author: b.tukhtashev@yandex.com
} 
thousands of hectares of land that have fallen out of agricultural use will be re-introduced into the farming system. This is one of the current issues of today $[9,10]$.

In solving this problem, the resistance to salinity, yield and product quality of agricultural crops (alfalfa, sunflower, white sorghum, sorghum, beet) grown on weak, moderate and strongly saline soils are studied and scientifically substantiated $[11,12]$. Technologies for growing these crops will be developed depending on soil and climatic conditions and salinity levels.

\section{Materials and methods}

The field experiment was conducted on weak, medium, strongly saline soils of the 'White Gold Lops Agro' farm in the Ak-altin district of Syrdarya Province, Uzbekistan. The experiment was carried out against a background of three different soils (weak, medium, strongly saline) and through a system of planting alfalfa, sunflower, oats, and hay beet.

The field experiment was set in 4 repetitions in 4 variants. The options were placed in a single tier. Furrow length was $50 \mathrm{~m}$ and each variant was obtained in 8 rows, i.e. at the expense of one visit of the seeder $\left(8 \times 70 \mathrm{~cm}=5.6\right.$ meters, $5.6 \times 50$ meters $\left.=280 \mathrm{~m}^{2}\right)$. The total area of each plot is $280 \mathrm{~m}^{2}$, the calculated area is $140 \mathrm{~m}^{2}$. Therefore, the total area of the experiment is $5,600 \mathrm{~m}^{2}$, and the calculated area is $2,160 \mathrm{~m}^{2}$.

The object of the experiment was the cultivation of corn - "Kora Bosh" farm, sunflower - "Jahongir" farm, beet - "Giant" farm, and alfalfa - "Tashkent-1" farm and their resistance to salinity.

The volumetric mass of the soil was determined by taking soil samples whose natural state was not disturbed. Soil water permeability by 6-hour tillage method developed by UzPITI. Soil moisture is determined before and after each watering by the method of drying in a thermostat. The limited field moisture capacity was determined by filling the area with water (ROM method) at point 2 of the experimental field. The level of salinity of the soil in the experimental field is determined by the amount of seasonal salt accumulation $(0-100$ $\mathrm{cm})$. The amount of water supplied to the field is accounted for by the Chipoletti (VCH-25) and the amount of wastewater Thomson (VT-90) water meter [11-13].

The date the crops were planted was recorded; - Lawn production - the beginning of germination; time of emergence; -Shonalization-time of onset and time of peak; Flowering- time of onset and time of flowering; and -Determined- the time of onset and the time of completion;

After harvesting under field conditions, 25 plants were taken from each plot, first wet mass and then dry mass were calculated.

In order to determine the agrochemical parameters of the experimental field soil, mixed soil samples from 0-30 and 30-50 cm soil layers were taken from 5 points of the field in the spring (Fig. 1). NPK, its general and mobile forms, humus, humus content were submitted to the laboratory for analysis.

During the experiment, soil moisture and agrochemical analyzes were performed rapid analyzes using newly acquired laboratory instruments during project implementation (Fig. $1)$. 


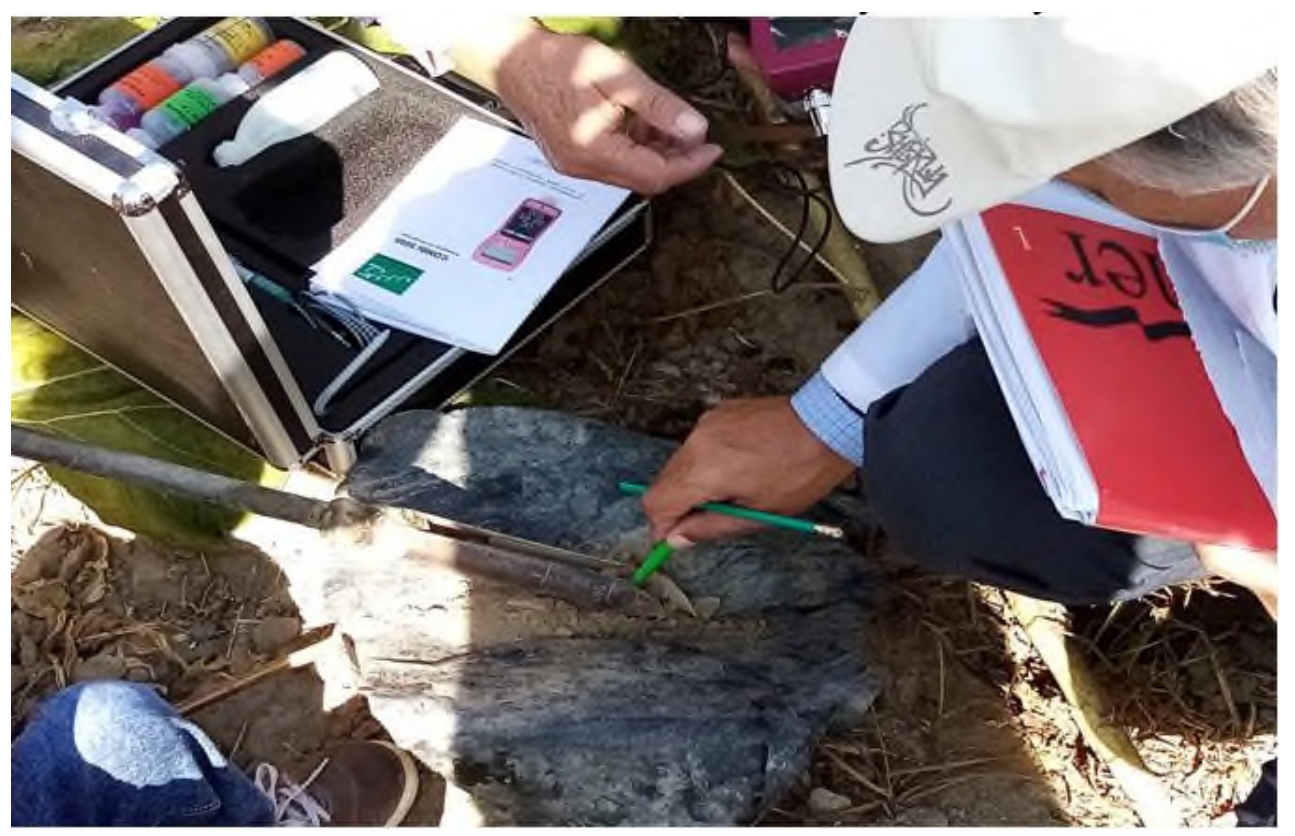

Fig. 1. Field soil sampling for soil moisture and agrochemical analysis prior to research (rapid analysis using laboratory instruments acquired during the project implementation).

\section{Results and discussion}

The agro-ameliorative importance of alfalfa in saline soils is very important. Therefore, the study of alfalfa cultivation technology in saline soils is of great importance today. This is because the heating of the soil surface is reduced by covering the soil surface with the biomass of alfalfa. As the soil surface heating decreases, the evaporation of water from the soil decreases. Reducing evaporation from the soil surface reduces the rise of groundwater. This is important in preventing soil salinization. As a result, moisture evaporation from the bed is reduced and salt accumulation does not occur.

Second, alfalfa improves the structure, water-physical properties of the soil, and as a result, the movement of water in the soil becomes more active, penetrates deeper and makes the soil saline. The roots of alfalfa penetrate very deep (3-4 $\mathrm{m}$ and deeper) and evaporate the groundwater $\left(10-15,000 \mathrm{~m}^{3} / \mathrm{ha}\right)$, which leads to a decrease in the groundwater level. After alfalfa, water consumption for crops grown on lands with increased soil fertility is significantly reduced (15-20\%). In the first year after planting alfalfa stalks, it is possible to get a rich harvest from the next crop without washing the soil with salt.

During the growing season, soil moisture was maintained at $70-80 \%$ relative to the limited field moisture capacity for high yields from alfalfa. Although alfalfa formed flat seedlings in the first year after planting, young seedlings are very resistant to the effects of salt. Taking this into account, the alfalfa was irrigated twice at the rate of $600-700 \mathrm{~m}^{3} / \mathrm{ha}$ before the period of stem formation or accumulation.

In determining the yield of alfalfa, the number of stems per $1 \mathrm{~m}^{2}$, green and dry mass, as well as the yield on plot were calculated separately in the order obtained.

Under weakly saline soils, the average number of stalks per $1 \mathrm{~m} 2$ of alfalfa before the first harvest was 172.5 , the yield of green mass was $1,212.5 \mathrm{~g}$ and the dry mass was 163.75 g. In particular, the average yield of alfalfa was 121.2 quintals (q)/ha in terms of green mass and $18.6 \mathrm{q} / \mathrm{ha}$ in terms of dry hay. 
In the second crop, the number of stems per $1 \mathrm{~m}^{2}$, green mass and dry hay yield increased due to the increase in the number of alfalfa bushes and the acceleration of plant growth. The number of stems per $1 \mathrm{~m}^{2}$ is 188.7 or 16 before the first harvest, the green mass is $1280 \mathrm{~g}$, the dry hay yield is $180 \mathrm{~g}$, and finally the green mass yield per hectare is 126 $\mathrm{q} / \mathrm{ha}$, and the dry hay yield is $20.8 \mathrm{q} / \mathrm{ha}$. ha, which is $2.2 \mathrm{q} / \mathrm{h}$ a more than the first harvest.

In the third crop, the number of stems per $\mathrm{m}^{2}$, green mass and dry hay yield increased due to the acceleration of plant growth in weakly saline soils, and finally the green mass yield per hectare was $132 \mathrm{q} / \mathrm{ha}$, and the dry hay yield was $23.8 \mathrm{q} / \mathrm{ha} .5 .2 \mathrm{q} / \mathrm{ha}$ more than the first harvest and $3.0 \mathrm{q} /$ ha more than the second harvest. From weakly saline soils, the yield of alfalfa in the second year was $63.2 \mathrm{q} / \mathrm{ha}$ at the expense of the third harvest. The condition of alfalfa in the field with weakly saline soils is shown in Fig. 2 below.

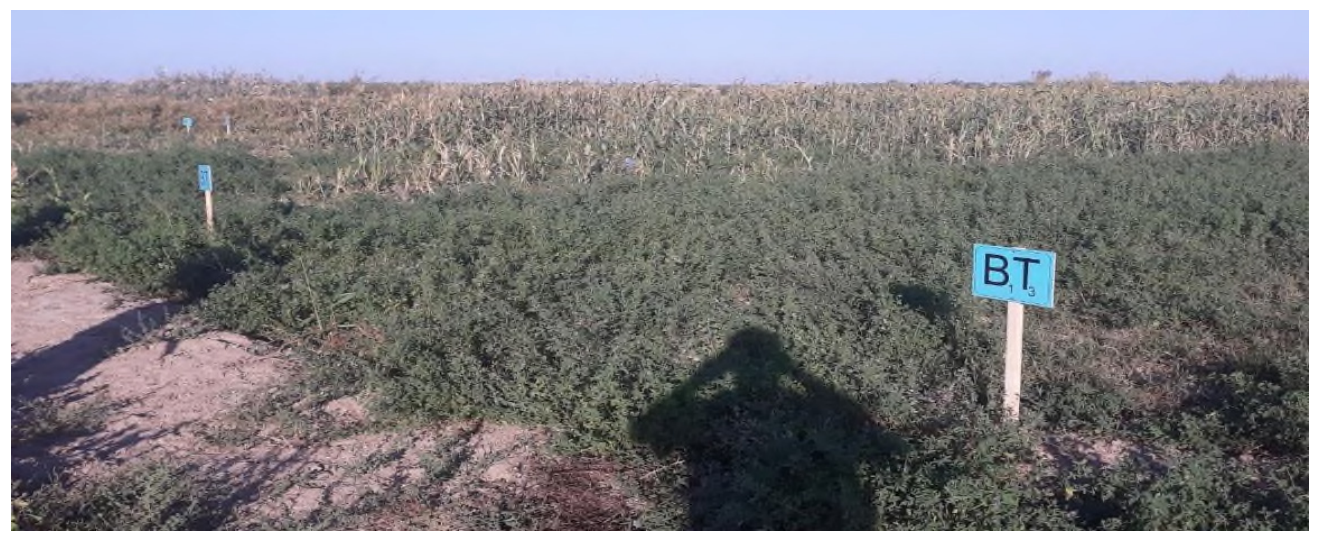

Fig. 2. Condition of alfalfa reared in weakly saline soils.

Under moderately saline soils, the average number of stems per $\mathrm{m}^{2}$ before the first harvest was 128.2, the yield of green mass was $927.5 \mathrm{~g}$ and the dry mass was $117.0 \mathrm{~g}$. The average yield of alfalfa was $91.7 \mathrm{q} / \mathrm{ha}$ in terms of green mass and $15.3 \mathrm{q} / \mathrm{ha}$ in terms of dry hay.

In the second crop, the number of stems per $1 \mathrm{~m}^{2}$, green mass and dry hay yield increased due to the increase in the number of alfalfa bushes and the acceleration of plant growth. The number of stalks per $1 \mathrm{~m}^{2}$ is 131.0 , the green mass is $960.5 \mathrm{~g}$, the dry hay yield is $127.2 \mathrm{~g}$, and finally the green mass yield per hectare is $90.45 \mathrm{q} / \mathrm{ha}$, and the dry hay yield is $16.3 \mathrm{q} / \mathrm{ha}$. an increase of 2.0 quintals compared to the first harvest.

In the study, even before the third harvest of alfalfa, the number of stems per $1 \mathrm{~m}^{2}$, green mass and dry hay yield were calculated on delyans. In the third harvest, the dry hay yield according to the study was $15.4 \mathrm{q} / \mathrm{ha}, 0.1 \mathrm{q} /$ ha more than in the first harvest, and 0.9 $\mathrm{q} /$ ha less than in the second harvest. In moderately saline soils, alfalfa yielded $47.0 \mathrm{q} / \mathrm{ha}$ at the rate of 3 rd harvest.

An increase in salt content of $0.5-1.0$ and even 2.0 per cent in strongly saline soils initially killed young seedlings and later formed plants. Studies were not continued after this option did not have adequate vegetation cover.

Sunflower is also an intermediate crop in terms of salt resistance. However, in the initial period of growth and development of the plant in the soil, the increase in the amount of salt to $0.5-1.0 \%$ of the dry weight of the soil affects its growth and development. This was once again reflected in the data obtained.

The study noted a significant difference in the biometric calculations of sunflower between weak and moderately saline soils. In particular, under moderate and strongly saline soils, the effect of salt was evident in the early development of the plant and had a negative 
effect in the later developmental phases. Overall, plant height was $13 \mathrm{~cm}$ in biometric calculations on June 1, 2019, $83.6 \mathrm{~cm}$ in calculations on July 1, 2019, and finally $130.4 \mathrm{~cm}$ on August 1,2019, significantly lagging behind plants grown in weakly saline variants. was observed. This has certainly had an impact on productivity.

In the case of weakly saline soils, the average yield of sunflower on the fourth turn was $106.6 \mathrm{q} / \mathrm{ha}$, while on average saline soils 90.8 or 15.6 ts less dry silage was obtained.

Sunflower is a plant that has the ability to grow well in weakly saline soils as well as in moderately saline soils. However, for this purpose it is advisable to increase the salt resistance (adaptation) or increase the flexibility of the plant during the initial period of growth and development.

One month after planting white oats or on the 15th or 16th day of germination, the plant is $19.4 \mathrm{~cm}$ tall and the 5th leaf has started to emerge. In the third period, which was 13.5 and finally biometric calculations were performed on the plant, on August 1 the plant height was $170.9 \mathrm{~cm}$ and the number of leaves was 15.9 (Fig. 3). Similar data were obtained on the growth and development of oats in the remaining returns. However, in the fourth return, biometric calculations performed three times showed certain differences in plant height and number of leaves. This can be explained by the partial violation of agro-technical measures carried out during the development of the plant. In general, in the biometric calculations conducted on July 1 on the 4th turn, the plant had a leaf height of $86.4 \mathrm{~cm}$ and a leaf count of 9.6, while in the calculations at the end of the growing season it produced $156.7 \mathrm{~cm}$ in height and 12.0 leaves, respectively.

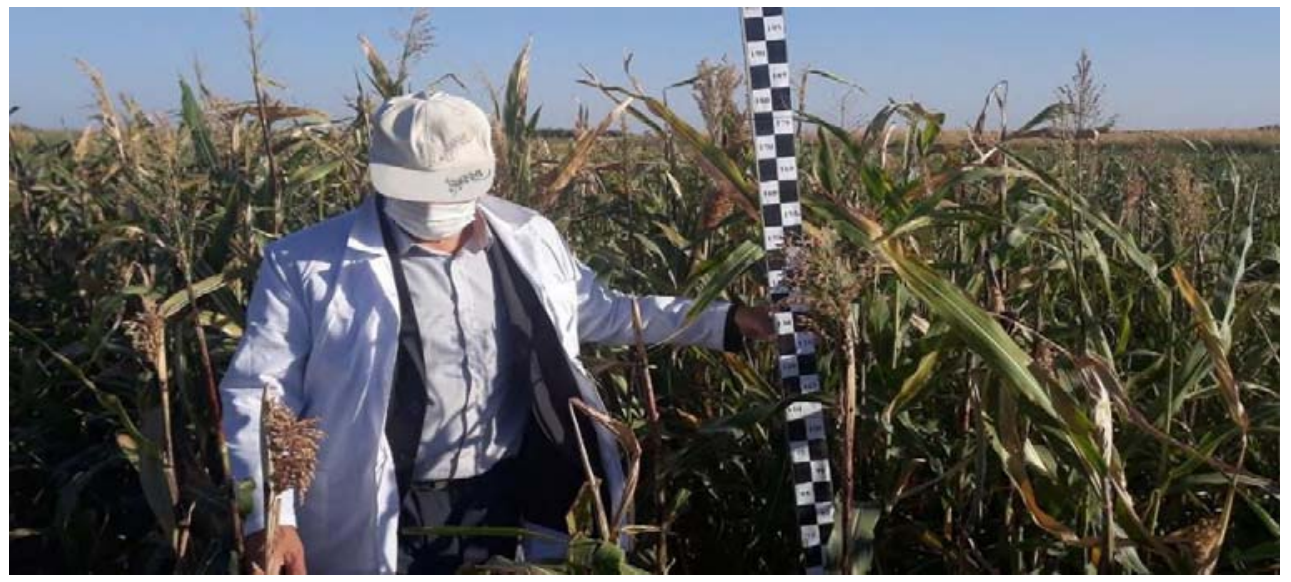

Fig. 3. Process of conducting biometric calculations in corn.

The effect of salt was noticeable in the early development of the plant, which also had a negative effect in the later developmental phases. In particular, in moderately saline soils, plant height was $15.0 \mathrm{~cm}$ in biometric calculations on June $1,78.2 \mathrm{~cm}$ on July 1, and finally $146.6 \mathrm{~cm}$ on August 1, 2019, significantly lagging behind plants grown in weakly saline variants. observed. This situation certainly has an impact on productivity.

In particular, in the experiments carried out on weakly saline soils, silage was obtained from $669.6 \mathrm{t} / \mathrm{ha}$ per hectare (in terms of wet mass), while in medium saline soils 580.7 quintals of silage was obtained.

Beet growth (Fig. 4) and development were determined 2 times per month. The calculations started on June 1 and ended on September 15. 


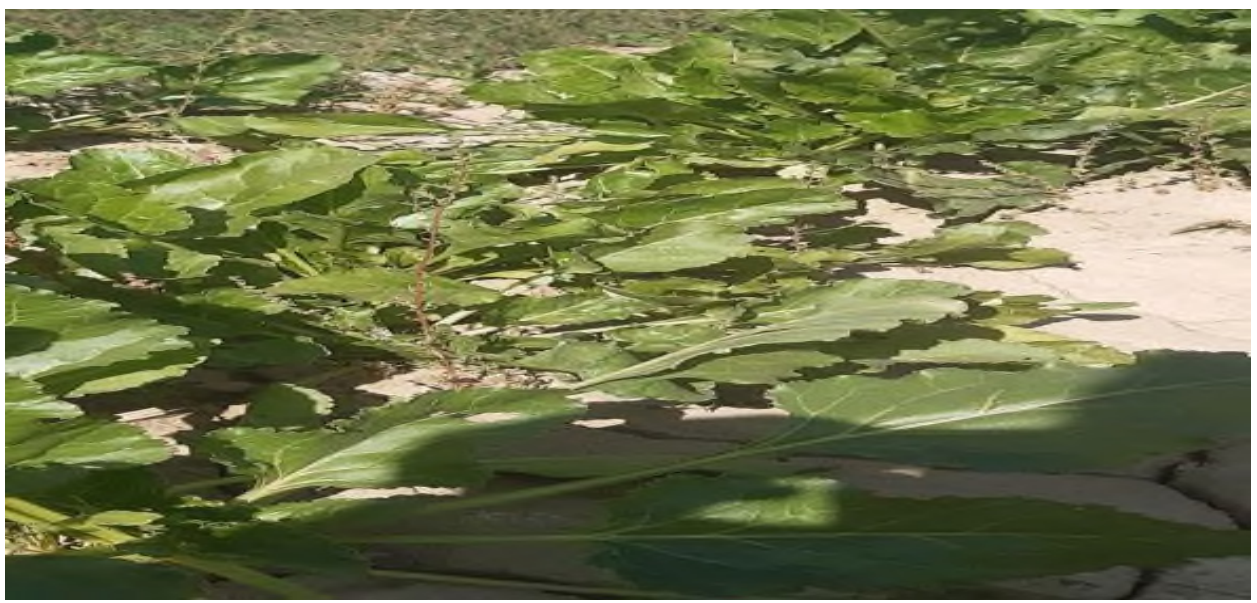

Fig. 4. Condition of beets planted in strongly saline soils.

In this case, the growth dynamics of leaves and tubers of beet was studied. The analysis showed that initially from June 1 to July 1, the weight of beetroot in the plant was high, but then, ie from July 15, the weight of beetroot increased significantly due to the acceleration of processes associated with the growth and development of tubers (Table 1). In particular, in the initial period, the ratio of leaf to root was 1.47 to 1.60 , but later this figure was transferred to the root account. This is directly related to the formation of tubers. In turn, this process is associated with rapid growth of the plant.

Table 1. Growth dynamics of beet leaves and tubers.

(in moderately saline soils)

\begin{tabular}{|c|c|c|c|c|}
\hline \multirow{2}{*}{$\begin{array}{c}\text { Dates of } \\
\text { sampling }\end{array}$} & \multicolumn{3}{|c|}{ Average weight of beet, $g$} & \multirow{2}{*}{$\begin{array}{l}\text { Leaf/root ratio } \\
\quad \text { (weight), } g\end{array}$} \\
\hline & Plant & Leaf & Beetroot & \\
\hline June 1, 2019 & 15 & 9 & 6 & 1.50 \\
\hline June 15,2019 & 105 & 65 & 40 & 1.60 \\
\hline July 1, 2019 & 225 & 134 & 91 & 1.47 \\
\hline July 15,2019 & 264 & 144 & 120 & 0.87 \\
\hline Aug 1, 2019 & 403 & 178 & 225 & 0.79 \\
\hline Aug 15, 2019 & 509 & 190 & 319 & 0.59 \\
\hline Sep 1, 2019 & 580 & 210 & 370 & 0.56 \\
\hline Sep15, 2019 & 623 & 225 & 398 & 0.56 \\
\hline
\end{tabular}

Especially after July 15 , the growth and development of the root is faster than that of the upper part of the plant, and finally, by the end of its development, the growth of the leaf relative to the root is 0.56 , which indicates twice the growth and development of the root.

In this case, 25 plants were selected from each plot. When determining productivity indicators, the root yield obtained in each return was multiplied by the number of seedlings per hectare.

It turns out that the growth environment of the plant has a significant impact on root yield. Initially, in the process of growth and development, beets grow well under these conditions, which is achieved in its later stages of development. In particular, the yield of beet root crops grown in poorly saline soils was $458.1 \mathrm{t} /$ ha (Table 2). 
Table 2. Yield of agricultural crops under saline soils.

\begin{tabular}{|c|c|c|c|c|c|c|}
\hline \multirow[b]{2}{*}{ \# } & \multirow[b]{2}{*}{ Crops } & \multicolumn{4}{|c|}{ Yield obtained by iterations, $q / h a$} & \multirow{2}{*}{ 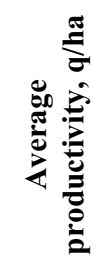 } \\
\hline & & $\mathbf{I}$ & II & III & IV & \\
\hline \multicolumn{7}{|c|}{ Weakly saline soils } \\
\hline 1 & Alfalfa & 61.8 & 64.1 & 64.9 & 62.2 & 63.2 \\
\hline 2 & Sunflower & 111.0 & 101.4 & 107.7 & 105.2 & 106.6 \\
\hline 3 & Corn & 675.3 & 660.7 & 687.3 & 655.4 & 669.6 \\
\hline 4 & Beet & 455.6 & 460.5 & 445.6 & 470.7 & 458.1 \\
\hline \multicolumn{7}{|c|}{ Moderately saline soils } \\
\hline 1 & Alfalfa & 46.7 & 47.9 & 46.4 & 47.0 & 47.0 \\
\hline 2 & Sunflower & 95.4 & 90.6 & 89.6 & 87.7 & 90.8 \\
\hline 3 & Corn & 575.0 & 590.1 & 572.2 & 585.0 & 580.7 \\
\hline 4 & Beet & 390.6 & 402.2 & 409.0 & 401.5 & 401.1 \\
\hline
\end{tabular}

\section{Conclusions}

In order to obtain high yields of agricultural crops in the conditions of saline soils of Syrdarya province in Uzbekistan, it is expedient to first select, study and scientifically substantiate the plants that are suitable for the conditions of these soils on their salinity resistance.

\section{References}

1. Y. Peng, F. Li, N. Xu, R. Kulmatov, K. Gao, G. Wang, Y. Zhang, Y. Qiao, Y. Li, H. Yang, S. Hao, Q. Li, S. Khasanov, Chinese Journal of Eco-Agriculture, 29(2), 312-324 (2021)

2. S. Isaev, S. Khasanov, Y. Ashirov, A. Gofirov, T. Karabaeva, In E3S Web of Conferences, 244, 02047 (2021)

3. R. Kulmatov, A. Taylakov, S. Khasanov, Environmental Science and Pollution Research, 28(10), 12245-12255 (2021)

4. S. K. Isaev, R. U. Rakhmonov, S. S. Tadjiev, G. I. Goziev, S. Z. Khasanov, In IOP Conference Series: Earth and Environmental Science, 614(1), 012147 (2020)

5. N. Teshaev, B. Mamadaliyev, A. Ibragimov, S. Khasanov, InterCarto. InterGIS, 26(3), 324-333 (2020)

6. R. A. Kulmatov, S. A. Adilov, S. Khasanov, In IOP Conference Series: Earth and Environmental Science, 614(1), 012149 (2020)

7. I. Aslanov, S. Khasanov, Y. Khudaybergenov, M. Groll, Ch. Opp, F. Li, E. Ramirez Del-Valle, In E3S Web of Conferences, 227, 02005 (2021)

8. B. Alikhanov, M. Juliev, S. Alikhanova, I. Mondal, Groundwater for Sustainable Development, 12, 100548 (2021)

9. N. Ch. Namozov, D. A. Kodirova, M. I. Usmonova, International journal of scientific \& technology research, 9(03), 5491-5493 (2020) 
10. S. Isaev, S. Khasanov, Y. Ashirov, T. Karabaeva, A. Gofirov, In E3S Web of Conferences, 244, 02012 (2021)

11. B. Tuktashev, CH. Toshpulatov, I. Rakhmonov, B. Mavlonov, International Journal of Multidisciplinary Research, 4285-4291 (2020)

12. B. Tuktashev, CH. Toshpulatov, M. Ajiniyazova, U. Gaziev, International Journal of Research Development, 1471-1476 (2020)

13. L. Gafurova, G. Djalilova, O. Ergasheva, D. Kadirova, Journal of Critical Reviews, 7(2), 283-287 (2020) 